\title{
Analysis of the Effectiveness of the Administrative Talk to Environmental Supervision in China
}

\author{
Ya Chen, Yankun Zhou \\ Management School, Jinan University, Guangzhou, China \\ Email:perfectmbo@163.com
}

How to cite this paper: Chen, Y. and Zhou, Y.K. (2016) Analysis of the Effectiveness of the Administrative Talk to Environmental Supervision in China. Open Journal of Business and Management, 4, 716-730. http://dx.doi.org/10.4236/ojbm.2016.44070

Received: September 5, 2016

Accepted: October 4, 2016

Published: October 7, 2016

Copyright $\odot 2016$ by authors and Scientific Research Publishing Inc. This work is licensed under the Creative Commons Attribution International License (CC BY 4.0).

http://creativecommons.org/licenses/by/4.0/

\begin{abstract}
The system of the administrative talk to environmental supervision is one of the internal supervision systems of the new Environmental Protection Law. The ministry of environmental protection has had administrative talks with the main government principals of about thirty cities since 2014 in which year China put forward the concept of new environmental normality. Through analyzing information of administrative talks and environmental data, we find out that the ministry of environmental protection achieved its goals in a mild way by having talks with the main government principals like their mayors without too much direct administrative intervention. Administrative talk of environmental protection has positive influence on solving major environmental problems and strengthening environmental law-enforcing supervision in short term. But practice in establishing the system of executive environmental responsibility and the system of environmental accountability are still needed.
\end{abstract}

\section{Keywords}

Administrative Talk of Environmental Protection, Government Environmental Responsibility, Environmental Law-Enforcing Supervision

\section{Introduction}

With the Chinese economy stepping into the new stage of sustainable development and innovation, the construction of ecological civilization and environmental protection face new challenges. For the actual implementation of environmental-protection work in China, Ministry of Environmental Protection of the People's Republic of China has been conscious of defining the obligations of local governments in the field of environmental protection and increasingly improves the awareness of accountability of local governmental departments. In May, 2014, Ministry of Environmental Protection issued Interim Procedures on Administrative Talk Held by Ministry of Environmental 
Protection (hereafter called Interim Procedures), which aims at inviting the main responsible persons of local governmental departments for a chat so as to actually and effectively implement the work of environmental protection.

This paper used the issue of supervising governance and administrative talk for environmental protection for the research object. At first, the background of mechanism of supervising governance and administrative talk for environmental protection was introduced. The overall status of administrative talk was comprehensively described from the perspectives of the time of administrative talk, the specific persons invited for a chat, reasons, methods and effects. Next, the corrective measures conducted by cities whose main responsible persons have been invited as well as the supervisory measures conducted by Ministry of Environmental Protection were represented, with the sustainability of effects of administrative talk being analyzed. At last, provinces to which the cities invited for a chat were defined as the experimental group, and Propensity Score Matching (PSM) was used for the establishment of the reference group. Changes of environmental-protection data before and after the occurring of administrative talk were compared and analyzed, disclosing the effects of system of supervising governance and administrative talk for environmental protection.

\section{Supervising Governance and Administrative Talk for Environmental Protection}

\subsection{Definition of Supervising Governance and Administrative Talk for Environmental Protection}

Administrative talk is an administrative and supervisory means commonly used by many countries and regions [1], such as the administrative talk for taxation over tea in Canada and coffee-drinking system in HK. In September of 2002, Liao Ning Local Taxation Bureau issued the notification for Administrative Talk for the Individual Income Tax of Outlanders (Number: Liaoning Local Taxation [2002] 296), which is the first of administrative talk system in China's administrative field [2]-[4]. Then, the administrative talk system has been widely applied in various governmental departments in relation to industry and commerce, health, taxation and real-estate management, resulting in good administrative effects and social benefits.

In May of 2014, the Ministry of Environmental Protection issued Interim Procedures on Administrative Talk Held by Ministry of Environmental Protection (hereafter called Interim Procedures), according to which the Ministry of Environmental Protection can invite related responsible persons of local governments or relevant departments whose obligations of environmental protection are neglected or unmet for a chat, during which an admonitory talk shall be conducted, related problems pointed out, corrective measures proposed and the implementation of these corrective measures supervised ${ }^{1}$.

The issuing of Interim Procedures marks the change from supervision of law enforcement only aiming at enterprises to the simultaneous occurring of supervising enterprises and governmental departments with supervising governance as the priority. It ${ }^{1}$ Definition of supervising governance and administrative talk for environmental protection comes from interim procedures on administrative talk held by Ministry of Environmental Protection. 
also includes the local governments and related departments into the accountability system of environmental protection and hones the accountability chains. Thus, the environmental regulation and accountability shall not be limited to responsible persons of local departments of environmental protection any longer. The accountability of leaders of local governments on environmental protection shall be reinforced. The work of environmental protection shall be consciously emphasized and supported by political power from top to bottom. The implementation of System of Supervising Governance and Administrative Talk for Environmental Protection has established the new environmental supervision mode where both enterprises and governmental departments shall be supervised, promoting the accountability of local governmental departments working their environmental-protection goals [5].

\subsection{Targets of Administrative Talk and Supervising Governance for Environmental Protection}

\subsubsection{Cities Invited for Administrative Talk and Their Geographical Distribution}

According to Interim Procedures, after the examination and verification, Ministry of Environmental Protection can invite and chat with the responsible persons of local governments and related departments whose goals of environmental protection haven't be achieved, whose jurisdiction has serious risks of environmental pollution and in whose jurisdiction there are construction projects seriously polluting the environment.

Since the issuing of Interim Procedures in May of 2014 and by December 31, 2015, Ministry of Environmental Protection has invited the responsible persons of 22 cities for a chat, of which 4 cities come from Northeast China, 6 from Central China, 7 from Eastern China and 6 from Western China. 5 of these 22 cities are the capital of a province.

The statistics show the uniformly geographical distribution of cities having invited for an administrative talk. Besides, both the economically developed cities or laggedbehind cities have the possibility of being invited for a chat, which ends the rumor that economically developed cities enjoy the privilege in relation to environmental protection. The fact of capital city of a province being invited for a chat indicates that the invited objects are not decided by their political or economic status, which fully demonstrates the determination of our country on changing the developmental methods at the critical moment of economic transition.

Besides, 11 of the 22 cities invited for a chat have been awarded the glorious titles in relation to the construction of ecological civilization and environmental protection, accounting for $50 \%$ of the 22 cities; what' more, Shenyang, Linyi and Ma'anshan are reputed to be China's Model Cities for Environmental Protection. 14 of the aforesaid cities are excellent tourist cities, taking up 64\%.

\subsubsection{Participants and Forms of Administrative Talk}

By December 31, 2015, among the 22 cities having been invited for an administrative talk and excluding Changchun City which has had the closed-door administrative talk, 
the other 21 cities have publicly had the administrative talk, making up $95.5 \%$ of the total researched cities. Statistically, information indicates that 16 cities had their mayors or deputy mayors attending the administrative talk, making up $76.2 \%$ while 11 cities saw officials from provincial-level bureau of environmental protection being invited for a chat, which was $52.4 \%$.

According to Interim Procedures, participants of the administrative talk should disclose all relevant information except national secrets, business secrets and personal privacy, and if the circumstances permit, media or even the public can be invited for attending the meetings ${ }^{2}$. The author thinks that the public talk can effectively pressure the cities and their governments into actually implementing the environmental protection goals by taking advantages of the influences of supervision by public opinion.

Besides, the administrative talk inviting the responsible persons from the provincial-level bureau of environmental protection and cities can fully exert the influences of power transmission and power supervision in China's bureaucratic system and put pressure on the local departments and related departments, allowing the local governments to attach importance to the environmental-protection works from top to bottom, fully promoting the initiatives of medium-level and low-level personnel in relation to environmental protection, encouraging the related departments to exert the supportive effects upon environmental protection work, which shall guarantee the full implementation of corrective measures and the promotion of environmental protection on a regular basis.

In conclusion, the public administrative talk and inviting the responsible persons of the local governments are two important conditions for guaranteeing the effectiveness of administrative talk.

\subsection{Frequency of Administrative Talk}

From the perspective of time of administrative talk, from the date in September of 2014 when the responsible persons of Hengyang Government were invited by Ministry of Environmental Protection to the end of 2014, the responsible persons of total 6 cities have been invited for a chat while in 2015 this number has been added to 16 . The average frequency of administrative talk in 2014 was 0.75 per month while 1.4 per month in 2015. The following Figure 1 is the number of cities whose responsible cities being invited for a chat from September 2014 to December 2015 according to the statistical information.

Thus, as one of the internal supervisory systems for the environmental protection by governments which are regulated by the new Environmental Protection Law, system of supervising governance and administrative talk for environmental protection has been widely applied through the country with the official implementation of new Environmental Protection Law in 2015. The system of supervising governance and administrative talk for environmental protection as an important means for environmental protection has provided administrative-system guarantee for promoting the economic ${ }^{2}$ Quotes from interim procedures on administrative talk held by Ministry of Environmental Protection. 


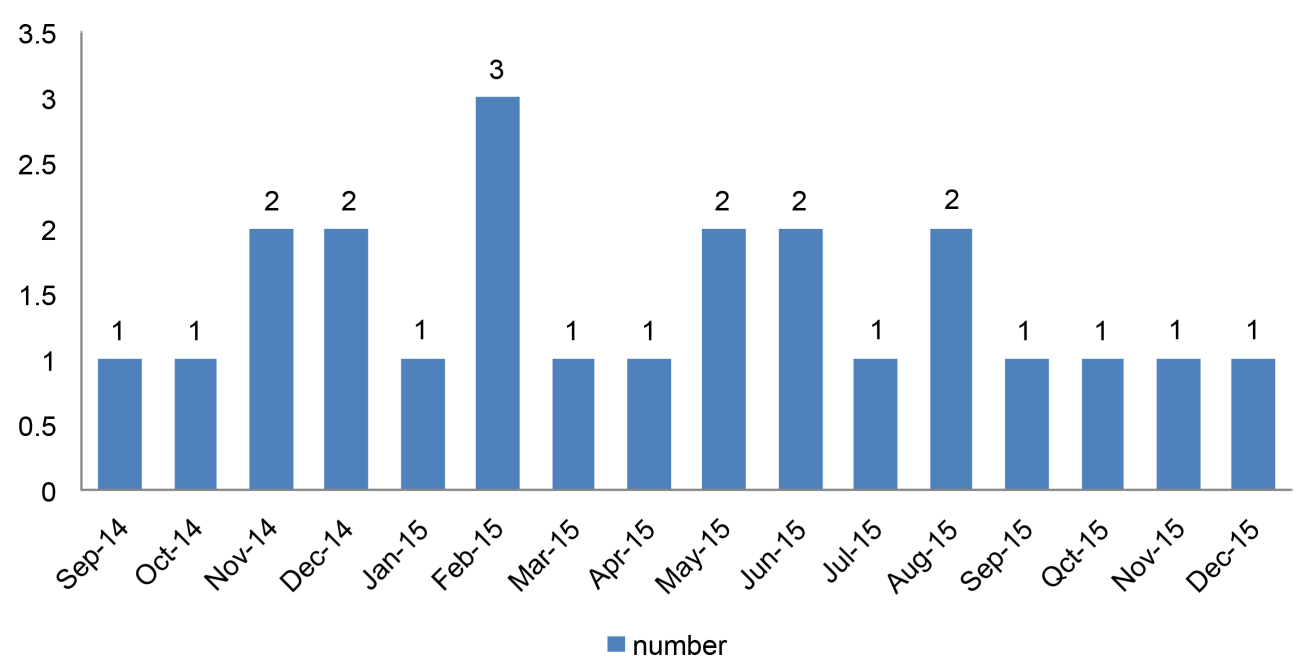

Figure 1. The number of cities invited for administrative talk in each month. (Notes: data from official website of Ministry of Environmental Protection).

transition and developing ecological civilization.

\subsection{Causes for Administrative Talk}

According to minutes and news reports, the author has classified the causes for administrative talk into two types, including 1) seriously environmental problems and 2) administrative problems, such as disqualified or regulation-or-rules-violating problems in the jurisdictions of the cities whose responsible persons invited for a chat.

\subsubsection{Environmental Problems Leading to Administrative Talk}

The four pollutants with the highest frequency in the minutes of meetings attended by the responsible persons of the above 21 cities are waste water, exhaust gas, solid pollutants and dusts. Thus, according to the frequency of these four kinds of pollutants appearing in the minutes of these 21 public meetings, the following Figure 2 can be obtained.

Figure 2 explicitly indicates that the frequency of waste water and waste gas appearing in the minutes is much higher than that of solid pollutants and dusts, which shows that by the endo of 2015, most of environmental problems involved with the administrative talks have come from atmospheric environment and water.

Secondly, the minutes of administrative talks show that except Zhangye, 9 of 21 cities were invited for talks because of no less than 2 kinds of problems in relation to environmental pollution, taking up 45\%. Besides, 3 cities were invited for a chat for 2 kinds of environmental-pollution problems and 4 cities for 3 kinds of problems.

\subsubsection{Administrative Problems Resulting in Administrative Talks}

Interim Procedures have regulated 11 circumstances for which administrative talks should be held. Except the 1st, 2nd and 5th circumstances specifying the seriously ecological and environmental problems which have occurred or have the potential of occurring, the other 8 circumstances are involved with environmentally administrative 


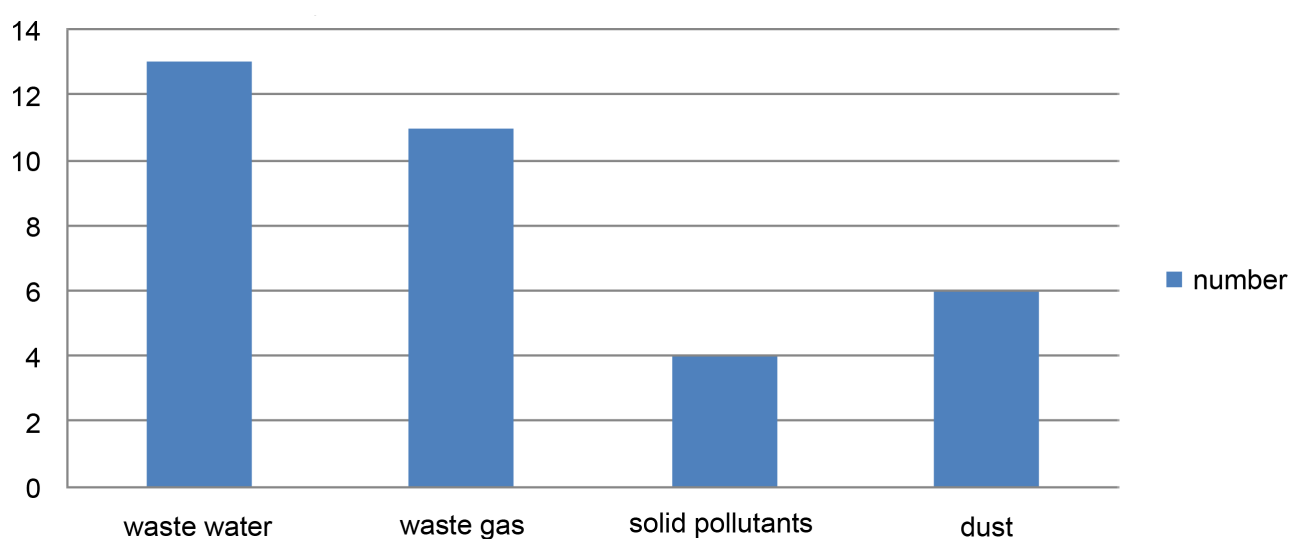

Figure 2. Pollutants involved with cities invited for administrative talks. (Notes: data from official website of Ministry of Environmental Protection).

problems, such as disqualification or violating laws, rules or regulations.

BaoQun (2013) conducted researches and indicated that the degree of law enforcement at the local level had the critical impacts on the effects of legislation [6]. Loose enforcement shall result in poor regulatory effects or negative influences even though the environmental legislation had been approved. Various problems in relation to law enforcement, such as supervisory negligence of local governments and the lack of governmental mechanism have to some degrees worsened the environmental problems, such as illegal emission of pollutants, which becomes the importantly influential factors to environmental and pollution problems.

The system of supervising governance and administrative talk for environmental protection happens to be the internal supervisory system dealing with such circumstances, which changes the central points of administrative talk from supervising enterprises to simultaneously supervising enterprises and governments, with the supervising enterprises as its priority. The methods previously used by Ministry of Environmental Protection were based on point-to-point basis, hoping to improve the environmental quality at local regions by inviting the enterprises for a chat. However, lacking the long-term strict supervision of local governments, the effects of administrative talks couldn't be sustainable. Thus, administrative talks with enterprises can't fundamentally solve the environmental problems. Administrative talk on the purpose of supervising governments is equal to megaphone, allowing to put pressure on local governments and related departments who could directly communicate with enterprises, supervising local governments to improve the degree of implementing environmental laws through which equally pressures enterprises, thus yielding twice the result with half the efforts.

\section{Corrective Measures after the Administrative Talk}

\subsection{Corrective Measures Required by the Administrative Talks Held by Ministry of Environmental Protection}

Aside from the administrative talks with responsible persons of Zhangye City aiming at natural reserves inside its jurisdiction, the other administrative talks were associated 
with the environmental problems of the whole administrative regions. Thus, the author statistically analyzed the minutes of public administrative talks with responsible persons of 20 cities. The statistic information indicated that the corrective measures proposed by the Ministry of Environmental Protection for cities having been invited for a chat can be classified into 10 types as specified at Table 1 .

\subsection{Supervisory Measures Taken by Ministry of Environmental Protection after the Administrative Talks}

Although no rules or regulations ever expressly providing for the administrative penalties associated with the administrative talks, as the direct and effective supervisory measure, the system of supervising governance and administrative talk for environmental protection can greatly motivate and pressure the local governments. Therefore, generally the corrective measures proposed at the administrative talks can greatly draw the attention of local governments.

\subsubsection{The Administrative Measures for Cities Invited for a Chat}

For the 22 pieces of minutes, tree kinds of administrative measures for cities invited for a chat were mentioned, including restrictive authorization of a region, supervising the implementation as well as starting procedures of removing the tiles of China's Model Cities for Environmental Protection.

The method of restrictive authorization of a region was firstly mentioned at the administrative talk with responsible persons from Shenyang and Harbin Governments held by Ministry of Environmental Protection. For the unaccomplished tasks of a certain

Table 1. Classification chart for corrective measures proposed by ministry of environmental protection.

\begin{tabular}{|c|c|}
\hline Requirements for Corrective Measures & Frequency of Being Proposed \\
\hline Establish Responsibility and Accountability Systems & 11 \\
\hline Reinforce the Degree of Supervising and Regulating Enterprises & 11 \\
\hline $\begin{array}{l}\text { Establish Long-Term Mechanism to Ensure the } \\
\text { Non-Occurring of Same Environmental Problems }\end{array}$ & 7 \\
\hline $\begin{array}{l}\text { Take Advantage of Administrative and } \\
\text { Economic Means to Solve the Environmental Problems }\end{array}$ & 18 \\
\hline Improve the Awareness and Improve the Levels of Law Enforcement & 10 \\
\hline $\begin{array}{l}\text { Make Arrangements in Advance According to the } \\
\text { Potential Environmental Problems inside the Region in the Future }\end{array}$ & 1 \\
\hline Implement the Administrative Accountability System & 2 \\
\hline $\begin{array}{l}\text { Publicize the Progress of Corrective Measures and } \\
\text { Accept the Supervision by the Public }\end{array}$ & 1 \\
\hline $\begin{array}{l}\text { Input Funds and Personnel to Ensure the Sufficient Provision of } \\
\text { Personnel and Equipment for Supervising and Examining }\end{array}$ & 1 \\
\hline $\begin{array}{l}\text { Stop Examining and Approving the Environmental } \\
\text { Review of the Subordinate Administrative Regions inside Its Jurisdiction }\end{array}$ & 1 \\
\hline
\end{tabular}

Note: From the official website of Ministry of Environmental Protection of the People's Republic of China. 
period, Ministry of Environmental Protection shall stop approving all projects within the aforementioned regions excluding the livelihood projects, energy saving and emission reduction, ecological and environmental protection and construction of infrastructure $^{3}$. For now, Both Shenyang City and Harbin City haven't implemented this measure.

The method of supervising the implementation means through means such as keeping the public informed, the higher-level governments and competent administrative departments should supervise the handling the serious cases and the implementing of corrective measures within the agreed period ${ }^{4}$.

The method of starting procedures of removing the tiles of China's Model Cities for Environmental Protection was established for three cities with the title of China's Model City for Environmental Protection. It was pointed out at the administrative talk with responsible persons of Ma'anshan Government, this method shall be used if the supervisory personnel discover in the subsequent examinations that the environmental problems couldn't be corrected satisfyingly within the agreed period. Removing the glorious title, exposing the local government under the public opinion and pressuring the government can effectively supervise the local government's actual constructing of ecological civilization.

The above three methods were administrative measures mentioned at the minutes of administrative talks. However, they can't represent all applicable supervisory measures.

\subsubsection{Administrative Penalties for Enterprises}

Although the system of supervising governance and administrative talk for environmental protection is the innovation for defining and supervising government's obligations, in the process of sorting out 21 pieces of minutes of administrative talks, author found that Ministry of Environmental Protection had prepared the administrative penalties for enterprises, including stopping construction and production and imposing a fine. For example, the administrative talk with responsible persons of Linyi City and Chengde City expressly regulated that three enterprises whose construction projects violating the rules and regulations should be stopped and corrected and a fine of $¥ 100,000 \mathrm{RMB}$ was imposed.

\section{Analysis of Effects of Administrative Talks}

To verify the effects of system of supervising governance and administrative talk for environmental protection, this paper used the provinces to which cities invited for a chat belong as the experimental group and the PSM method was employed to assign a reference group to match the province to which a city invited for a chat belongs. Then the relevant data was compared and analyzed. Specifically, we used the binary choice model (probit) to evaluate the probability of all provinces being invited for a chat and calculated this probability according to the results of evaluation (i.e. values of propen${ }^{3}$ Quote from the minutes of administrative talks with responsible persons from Shenyang City and Harbin City, Ministry of Environmental Protection Invited Responsible Persons of Governments of Shenyang City and Harbin City and Supervise the Implementation of Corrective Measures by Related Enterprises.

${ }^{4}$ Quote from BaiduBaike. 
sity score) to get the reference group whose probability value is closest to the experimental group. In the process of predicting the probability of each province getting invited for a chat, according to the existing literature, we chose the following indexes: discharge capability per unit of GDP and its growth rate a year before the occurring of administrative talk, the log value of per capital GDP a year before the occurring of administrative talk, the proportion of value of industrial output in the local economy as well as the degree of pollutant discharge. Through matching, the following table was gotten.

According to the availability of data, the experimental group only used provinces whose one or more than one cities had been invited for a chat by July 1, 2015. The reference group was obtained by matching after removing all provinces whose one or more than one cities had been invited for a chat.

In this paper, the analysis of effects of administrative talks was conducted by using three indexes, including air quality index, the levels of air quality and total amount of pollution discharge fees paid by enterprises monitored by the country. The time range of data being collected was the two quarters before and after the data of occurring of administrative talk.

\subsection{Improved Air Quality}

\subsubsection{Air Quality Index}

This paper firstly collected the AQI of cities affiliated to the provinces (or municipalities or autonomous regions) at Table 2. Then the AQI of each quarter within the corresponding period for each province (or municipality or autonomous region) was

Table 2. Province invited for a chat and its matching province.

\begin{tabular}{ccc}
\hline $\begin{array}{c}\text { Province Invited for A } \\
\text { Chat }\end{array}$ & $\begin{array}{c}\text { Matching Province (Municipality or Autonomous } \\
\text { Region) }\end{array}$ & $\begin{array}{c}\text { Time of Administrative } \\
\text { Talk }\end{array}$ \\
\hline Anhui Province & Zhejiang Province & June 18, 2015 \\
Guizhou Province & Xinjiang Uygur Autonomous Region & October 13, 2014 \\
Hebei Province & Shanghai City & February 8, 2015 \\
Henan Province & Inner Mongolia Autonomous Region & November 5, 2015 \\
Heilongjiang Province & Ningxia Hui Autonomous Region & December 30, 2014 \\
Hunan Province & Shaanxi Province & September 15, 2014 \\
Jilin Province & Chongqing City & November 2014 \\
Jiangsu Province & Guangdong Province & June 16, 2015 \\
Liaoning Province & Jiangxi Province & December 30, 2014 \\
Shandong Province & Hubei Province & February 25, 2015 \\
Shanxi Province & Tianjin City & May 12, 2015 \\
Sichuan Province & Fujian Province & June 22, 2015 \\
Yunnan Province & Hainan Province & January 13, 2015 \\
\hline
\end{tabular}

Note: The above data from the website site of Ministry of Environmental Protection. 
obtained for the preparing of Table 3. Positive value indicated that the AQI after the occurring of administrative talk was better than that before the occurring of administrative talk. Negative value indicted worse.

From the analysis of data from above table, it can be seen that among the 13 provinces (municipalities or autonomous regions) invited for a chat, the AQIs of 7 provinces one quarter or two quarters after the occurring of administrative talk were better than that of before the occurring of administrative talk, taking up 54\%. However, on the contrary, for the other 6 provinces (municipalities or autonomous regions) invited for a chat, their AQIs one quarter or two quarters after the occurring of administrative talk were worse than that before the occurring of administrative talk, indicating no obvious improvement for the air quality of the whole provincial area.

For the 4 matching provinces (municipalities or autonomous regions), their AQIs one quarter or two quarters after the occurring of administrative talk were worse than that before the occurring of administrative talk, taking up 30.8\% while for the other 9 matching provinces (municipalities or autonomous regions), 6 provinces had two indexes with negative values, equal to the provinces invited for a chat.

For 7 provinces invited for a chat and with 2 indexes having positive values, among their matching provinces, only 4 provinces saw their two indexes getting better among which, however three provinces had the values of two indexes higher than that of their corresponding provinces invited for a chat. This indicated that although the air quality of these provinces was better than that of before the occurring of administrative talk,

Table 3. Changes of AQI of each province.

\begin{tabular}{|c|c|c|c|c|c|}
\hline $\begin{array}{c}\text { Province Invited for A } \\
\text { Chat }\end{array}$ & $\begin{array}{l}\text { AQI Changes One } \\
\text { Quarter before or } \\
\text { after }((t-1)-(t+ \\
1)) /(t-1)\end{array}$ & $\begin{array}{l}\text { AQI Changes Two } \\
\text { Quarters before or } \\
\text { after }((t-2)-(t+ \\
2)) /(t-2)\end{array}$ & Matching Province & $\begin{array}{l}\text { AQI Changes One } \\
\text { Quarter before or } \\
\text { after }((t-1)-(t+ \\
1)) /(t-1)\end{array}$ & $\begin{array}{c}\text { AQI Changes Two } \\
\text { Quarters before or } \\
\text { after }((t-2)-(t+ \\
2)) /(t-2)\end{array}$ \\
\hline Anhui Province & $16.72 \%$ & $3.55 \%$ & Zhejiang Province & $5.22 \%$ & $6.81 \%$ \\
\hline Guizhou Province & $-46.00 \%$ & $-28.64 \%$ & Xinjiang Uygur Autonomous Region & $-18.62 \%$ & $-17.02 \%$ \\
\hline Hebei Province & $27.36 \%$ & $20.16 \%$ & Shanghai & $-9.93 \%$ & $-12.88 \%$ \\
\hline Henan Province & $-79.27 \%$ & $-35.23 \%$ & Inner Mongolia Autonomous Region & $-15.36 \%$ & $0.44 \%$ \\
\hline Heilongjiang Province & $10.70 \%$ & $2.44 \%$ & Ningxia Hui Autonomous Region & $-9.62 \%$ & $-17.49 \%$ \\
\hline Hunan Province & $-42.16 \%$ & $-32.31 \%$ & Shaanxi Province & $-49.31 \%$ & $-31.14 \%$ \\
\hline Jilin Province & $-53.90 \%$ & $-36.60 \%$ & Chongqing & $-58.53 \%$ & $-30.59 \%$ \\
\hline Jiangsu Province & $11.20 \%$ & $8.31 \%$ & Guangdong Province & $-20.29 \%$ & $-1.53 \%$ \\
\hline Liaoning Province & $-4.19 \%$ & $-7.06 \%$ & Jiangxi Province & $1.61 \%$ & $-5.30 \%$ \\
\hline Shandong Province & $16.38 \%$ & $13.39 \%$ & Hubei Province & $28.85 \%$ & $17.22 \%$ \\
\hline Shanxi Province & $29.57 \%$ & $16.03 \%$ & Tianjin & $38.94 \%$ & $23.82 \%$ \\
\hline Sichuan Province & $10.04 \%$ & $19.96 \%$ & Fujian Province & $26.53 \%$ & $23.64 \%$ \\
\hline Yunnan Province & $-3.08 \%$ & $-11.25 \%$ & Hainan Province & $3.38 \%$ & $-4.45 \%$ \\
\hline
\end{tabular}

Note: The raw date from official website of Ministry of Environmental Protection 
the degree of improvement of air quality for matching provinces was higher than that of provinces invited for a chat. Thus, the above data couldn't indicate that the administrative talk had obvious effects upon the improving of air quality.

Notably, except Sichuan Province, for other 6 provinces invited for a chat whose 2 indexes with positive values, the first value was higher than the second value, which indicated that the compared with the first two quarters, the degree of improving AQI for the latter two quarters was smaller than that of latter quarter. If the assumption that the air quality of these 7 provinces was improved because of the administrative talk could be established, then this data was capable of indicating that the administrative talk lacked the supervisory mechanism and long-term mechanism to some degree.

The AQI can't effectively demonstrate that the administrative talk is capable of significantly improving the air quality.

\subsubsection{Levels of Air Quality}

The levels of air quality are associated with AQI. The levels of air quality can be defined as the proportion of days when the AQIs are rated as excellent or good within certain span of time. By collecting the AQI data, this paper calculated the changes of levels of air quality of provinces invited for a chat and of matching provinces before and after the occurring of administrative talk as followed at Table 4. Positive values indicated that the levels of air quality after the occurring of administrative talk were better than that of before the occurring of administrative talk while the negative values indicated

Table 4. Changes of levels of air quality of each province.

\begin{tabular}{|c|c|c|c|c|c|}
\hline & Changes of Levels of & Changes of Levels of & & Changes of Levels o & Changes of Levels of \\
\hline $\begin{array}{c}\text { Provinces Invited for A } \\
\text { Chat }\end{array}$ & $\begin{array}{l}\text { Air Quality One } \\
\text { Quarter before or } \\
\text { after }((t+1)-(t- \\
1)) /(t-1)\end{array}$ & $\begin{array}{l}\text { Air Quality Two } \\
\text { Quarters before or } \\
\text { after }((t+2)-(t- \\
2)) /(t-2)\end{array}$ & Matching Province & $\begin{array}{l}\text { Air Quality One } \\
\text { Quarter before or } \\
\text { after }((t+1)-(t- \\
1)) /(t-1)\end{array}$ & $\begin{array}{l}\text { Air Quality Two } \\
\text { Quarters before or } \\
\text { after }((t+2)-(t- \\
2)) /(t-2)\end{array}$ \\
\hline Anhui Province & $11.30 \%$ & $2.70 \%$ & Zhejiang Province & $-2.22 \%$ & $4.03 \%$ \\
\hline Guizhou Province & $-21.37 \%$ & $-20.37 \%$ & Xinjiang Uygur Autonomous Region & $-12.28 \%$ & $-19.83 \%$ \\
\hline Hebei Province & $20.49 \%$ & $17.10 \%$ & Shanghai & $-20.59 \%$ & $-9.66 \%$ \\
\hline Henan Province & $-68.42 \%$ & $-43.83 \%$ & Inner Mongolia Autonomous Region & $-17.11 \%$ & $-0.64 \%$ \\
\hline Heilongjiang Province & $10.53 \%$ & $2.10 \%$ & Ningxia Hui Autonomous Region & $-15.93 \%$ & $-20.68 \%$ \\
\hline Hunan Province & $-29.12 \%$ & $-28.59 \%$ & Shaanxi Province & $-39.15 \%$ & $-29.36 \%$ \\
\hline Jilin Province & $-37.56 \%$ & $-29.47 \%$ & Chongqing & $-41.98 \%$ & $-19.94 \%$ \\
\hline Jiangsu Province & $14.57 \%$ & $14.55 \%$ & Guangdong Province & $-5.19 \%$ & $0.70 \%$ \\
\hline Liaoning Province & $-1.34 \%$ & $-5.97 \%$ & Jiangxi Province & $-9.52 \%$ & $-6.48 \%$ \\
\hline Shandong Province & $22.58 \%$ & $19.56 \%$ & Hubei Province & $86.36 \%$ & $25.54 \%$ \\
\hline Shanxi Province & $48.54 \%$ & $33.79 \%$ & Tianjin & $85.44 \%$ & $64.82 \%$ \\
\hline Sichuan Province & $4.90 \%$ & $18.11 \%$ & Fujian Province & $1.51 \%$ & $3.35 \%$ \\
\hline Yunnan Province & $-1.12 \%$ & $-2.05 \%$ & Hainan Province & $0.57 \%$ & $0.26 \%$ \\
\hline
\end{tabular}

Note: The raw date from official website of Ministry of Environmental Protection. 
the worse.

By analyzing the above data, it can be concluded that for the 13 provinces (municipalities or autonomous regions) invited for a chat, the levels of air quality of 7 provinces one quarter or two quarters after the occurring of administrative talk were better than that of before the occurring, accounting for $54 \%$. On the contrary, for the other 6 provinces (municipalities or autonomous regions), the levels of air quality one quarter or two quarters after the occurring of administrative talk were lower than that of before the occurring.

For the matching provinces, the levels of air quality of only 4 provinces one quarter and two quarters after the occurring of administrative talk were higher than that of before the occurring, taking up 30.8\%. However, for the other 9 provinces, 7 provinces saw their two indexes having negative values. By comparing provinces invited for a chat and matching provinces, for 7 provinces invited for a chat and with 2 indexes getting better, only 3 of their matching provinces saw their two indexes getting better.

Notably, among 7 provinces with their two indexes having positive values, except $\mathrm{Si}$ chuan Province, other 6 provinces enjoyed the same tendency, which was the rate of improving levels of air quality one quarter after the occurring of administrative talk was higher than that of two quarters after the occurring. Except Fujian Province which matched Sichuan Province, the other 2 matching provinces enjoying positive values also had the same tendency, and their rates of improving were higher than that of provinces invited or a chat.

By analyzing the AQI and levels of air quality, it can be concluded that although number of provinces invited for a chat with their two indexes getting better is larger than that of provinces with two indexes getting worse, and the number of provinces invited for a chat with their two indexes getting better is larger than that of matching provinces, the comparing of provinces invited for a chat and their matching provinces showed that among provinces with their two indexes getting better, the degree of improvement of the matching provinces were generally higher than that of provinces invited for a chat. Thus, the author concluded that only relying on data of air quality on the provincial basis, the effectiveness of administrative talk can hardly be determined.

However, the author also though that the analyzing of these data revealed some problems. For ratios of changes of AQI and levels of air quality, among provinces with these two ratios rising one quarter and two quarters after the occurring of administrative talk, they showed the tendency that the ratio of rising at the latter two quarters was smaller than that of ratio at the latter one quarter. Thus, we can boldly conclude that although the administrative talk does have positive effects upon the improving of environment at provinces invited for a chat, due to the lacking of long-term mechanism, the effectiveness of administrative talk shall be weakened. The improvement occurring immediately after the holding of administrative talk shall be nullified by the flying of time. Thus, as far as the author was concerned, besides dealing with serious environmental problems of the cities invited for a chat, the administrative talk should also be involved with supervising the local government to quicken the construction of long- 
term mechanism for environmental protection. Meanwhile, It also should concentrate on the development of system of one post with two kinds of obligations, and strictly supervising and regulating the law enforcement to ensure the environmental protection shall be effectively supported by legislation and law-enforcing.

\subsection{Changes of Degree of Law-Enforcing by Local Government for Environmental Protection}

As one of environmental policies with most importance and longest duration, system of pollution charges can effectively reflect the degree of supervising the enforcement of environmental law. To further evaluate the influences of administrative talks upon the local governments' supervising of the enforcement of environmental law, this paper chose and analyzed the total amounts of pollution discharge fees paid by enterprises monitored by the country in each province on the purpose of understanding the local governments' supervising of the enforcement of environmental law from the perspective of changes of pollution discharge fees. According to the total amounts of pollution discharge fees paid by enterprises monitored by the country in each province, Table 5 could be obtained. The positive values indicated that the amount of pollution discharge fees paid by enterprises were larger than that of before the occurring of administrative talk while the negative values said the otherwise.

According to the analysis of above table, the pollution discharge fees paid by enterprises in 8 of 13 provinces invited for a chat one quarter and two quarters after the occurring

Table 5. Changes of pollution discharge fees paid by enterprises monitored by the country in each province.

\begin{tabular}{|c|c|c|c|c|c|}
\hline $\begin{array}{l}\text { Provinces Invited for A } \\
\text { Chat }\end{array}$ & $\begin{array}{l}\text { Changes of Pollution } \\
\text { Discharge Fees One } \\
\text { Quarter before or } \\
\text { after }((t+1)-(t- \\
1)) /(t-1)\end{array}$ & $\begin{array}{l}\text { Changes of Pollution } \\
\text { Discharge Fees Two } \\
\text { Quarters before or } \\
\text { after }((t+2)-(t- \\
2)) /(t-2)\end{array}$ & Matching Provinces & $\begin{array}{l}\text { Changes of Pollution } \\
\text { Discharge Fees One } \\
\text { Quarter before or } \\
\text { after }((t+1)-(t- \\
1)) /(t-1)\end{array}$ & $\begin{array}{l}\text { Changes of Pollution } \\
\text { Discharge Fees Two } \\
\text { Quarters before or } \\
\text { after }((t+2)-(t- \\
2)) /(t-2)\end{array}$ \\
\hline Anhui Province & $37.37 \%$ & $22.01 \%$ & Zhejiang Province & $-10.04 \%$ & $-12.83 \%$ \\
\hline Guizhou Province & $34.95 \%$ & $0.34 \%$ & Xinjiang Uygur Autonomous Region & $-5.11 \%$ & $-23.67 \%$ \\
\hline Hebei Province & $60.15 \%$ & $43.22 \%$ & Shanghai & $72.12 \%$ & $74.19 \%$ \\
\hline Henan Province & $-14.70 \%$ & $-20.67 \%$ & Inner Mongolia Autonomous Region & $-12.80 \%$ & $-24.58 \%$ \\
\hline Heilongjiang Province & $19.88 \%$ & $9.47 \%$ & Ningxia Hui Autonomous Region & $21.23 \%$ & $7.85 \%$ \\
\hline Hunan Province & $-1.16 \%$ & $-8.06 \%$ & Shaanxi Province & $2.08 \%$ & $-2.13 \%$ \\
\hline Jilin Province & $41.50 \%$ & $8.03 \%$ & Chongqing & $8.14 \%$ & $7.20 \%$ \\
\hline Jiangsu Province & $-3.40 \%$ & $1.48 \%$ & Guangdong Province & $-5.87 \%$ & $-0.69 \%$ \\
\hline Liaoning Province & $6.12 \%$ & $-6.32 \%$ & Jiangxi Province & $-12.53 \%$ & $-7.02 \%$ \\
\hline Shandong Province & $9.37 \%$ & $-9.60 \%$ & Hubei Province & $26.35 \%$ & $47.12 \%$ \\
\hline Shanxi Province & $59.51 \%$ & $18.61 \%$ & Tianjin & $-25.28 \%$ & $-16.96 \%$ \\
\hline Sichuan Province & $50.06 \%$ & $43.30 \%$ & Fujian Province & $-1.79 \%$ & $-5.23 \%$ \\
\hline Yunnan Province & $342.99 \%$ & $55.61 \%$ & Hainan Province & $-38.03 \%$ & $-30.48 \%$ \\
\hline
\end{tabular}

Note: The raw date from official website of Ministry of Environmental Protection. 
of administrative talk were more than that of before the occurring of administrative talks, accounting for $61.5 \%$. Besides, the percentages of rising of two indexes for 5 provinces were above $10 \%$. The other 3 provinces had one index rising with a rate of above $10 \%$. However, for these 8 provinces, the rising rate of latter two quarters was smaller than that of latter one quarter. Among the matching provinces, only 4 provinces saw rising rates of their two indexes after the occurring of administrative talks higher than that of before the occurring, accounting for $30.8 \%$. On the contrary, the number of provinces whose risking rates of two indexes before the occurring of administrative talks were higher than that of after the occurring was 8 , taking up $61.5 \%$.

By analyzing and comparing the provinces invited for a chat and matching provinces, it has been discovered that for 8 provinces invited for a chat and with two indexes having positive values, the matching provinces of aforesaid 6 provinces invited for a chat saw two indexes enjoying negative values. It indicated that after the occurring of administrative talks, the total amount of pollution discharge fees paid by enterprises in the provinces invited for a chat was increased while the total amount paid in matching provinces was decreased.

By analyzing the data of changes on pollution discharge fees paid by enterprises, it can be effectively proved both from the perspectives of longitudinal and lateral comparison that the administrative talks allowed the provinces invited for a chat to reinforce their charging enterprises for pollution discharge fees. In the author's opinion, since the amount of pollution discharge fees has always been an environmental-protection index paid much attention by the public, after being invited for a chat, the local governments shall reinforce their charging enterprises, resulting in the great rising of total amount of pollution discharge fees.

However, the above data also indicated that with the flying of time after the occurring of administrative talks, the rising rate for total amount of pollution discharge fees was greatly decreased. It told us that without the effective regulation and supervision, the local government would neglect their supervisory obligation upon the enterprises, and the effects of administrative talks would be weaken. It also proved the importance and necessity of promoting the establishment of long-term and effective environmental-protection mechanism. Otherwise, the administrative talk would never fundamentally solve the targeted problems.

According to the above analysis, the author thought that in the short term the administrative talks could significantly improve local governments' supervising of implementation of environmental laws. However, how to reinforce the effects of administrative talks by means of developing related systems and through incentives and penalties shall be further discussed and researched.

\section{Conclusion}

The system of supervising governance and administrative talk for environmental protection is an innovation under the circumstances of environmental protection on the regular basis and provides new thinking for furthering the environmental protection 
work. Aiming at environmental problems and serious administrative problems in relation to citizen's immediate interests, the Ministry of Environmental Protection publicly invited the responsible persons (e.g. mayor) of the government for a chat, defining the environmental-protection obligations which should be borne by the local government, and promoting the solving of environmental problems through taking advantage of supervision by public opinion and administrative supervision. Although the AQI and levels of air quality can hardly prove that the administrative talks have significant influences upon the improving of air quality, the changes of total amount of pollution discharge fees paid by enterprises clearly showed that in the short term, the administrative talks can improve the initiatives of local government supervising the implementation of environmental laws. However, to achieve the harmonious development of human being and the mother nature and to transform the environmental weakness into new economic growth point, various effective mechanism including environmental-protection obligation system and accountability system should be established. Meanwhile, the strengths of local government supervising the implementation of environmental laws should be reinforced. The environmental-protection awareness and obligations of local government should also be improved. The effective and long-term mechanism for environmental protection should also be explored.

\section{References}

[1] Liu, Y.M. (2015) Tax Audit System Analysis and Revelation of Canada. Taxation Research, 5, 90-91.

[2] Meng, Q.L. (2015) Study on Legalization of Administrative Talk. Administrative Law Review, 6, 99-118.

[3] Wang, H. and Wheeler, D. (2005) Financial Incentives and Endogenous Enforcement in China's Pollution Levy System. Journal of Environmental Economics \& Management, 49, 174-196. http://dx.doi.org/10.1016/j.jeem.2004.02.004

[4] Wang, H., Mamingi, N., Laplante, B. and Dasgupta, S. (2002). Incomplete Enforcement of Pollution Regulation: Bargaining Power of Chinese Factories. Environmental\& Resource Economics, 24, 245-262. http://dx.doi.org/10.1023/A:1022936506398

[5] Ge, C.Z., Wang, J.N. and Weng, Z.X. (2015) Research on Administrative Talk to Environmental Supervision. Environmental Protection, 12, 23-26.

[6] Bao, Q., Shao, M. and Yang, D.L. (2013) Environmental Regulation, Provincial Legislation and Pollution Emission in China. Economic Research Journal, 12, 42-54. 
Submit or recommend next manuscript to SCIRP and we will provide best service for you:

Accepting pre-submission inquiries through Email, Facebook, LinkedIn, Twitter, etc. A wide selection of journals (inclusive of 9 subjects, more than 200 journals)

Providing 24-hour high-quality service

User-friendly online submission system

Fair and swift peer-review system

Efficient typesetting and proofreading procedure

Display of the result of downloads and visits, as well as the number of cited articles

Maximum dissemination of your research work

Submit your manuscript at: http://papersubmission.scirp.org/

Or contact ojbm@scirp.org 